\title{
Análise dos dois principais fatores de decaimento da coluna total de Ozônio sobre o sul da América do Sul
}

\author{
Analysis of the main factors for events of ozone total column decay over southern \\ South America
}

\author{
Laís San Martins Schmalfuss ${ }^{* 1}$, Glauber Lopes Mariano², Damaris Kirsch Pinheiro², \\ Lucas Vaz Peres ${ }^{4}$ \\ ${ }^{1}$ Mestranda, Universidade Federal de Pelotas, Pelotas, Brasil \\ ${ }^{2}$ Doutor, Universidade Federal de Pelotas, Pelotas, Brasil \\ ${ }^{3}$ Doutor, Universidade Federal de Santa Maria, Santa Maria, Brasil \\ ${ }^{4}$ Doutor, Universidade Federal de Santa Maria, Santa Maria, Brasil
}

\begin{abstract}
Resumo
O ozônio (O3) é indispensável para a vida na Terra, pois absorve radiação ultravioleta do tipo B (UV-B) que é prejudicial para a saúde de seres vivos. Desde o início da década de 1980 relatou-se a existência de uma depleção na camada de ozônio sobre a Antártica e que esta poderia se mover para latitudes menores. O objetivo deste trabalho é a análise dos principais eventos de decaimento da coluna total de ozônio sobre a América do Sul $\left(20^{\circ} \mathrm{s}\right.$, $40^{\circ}$ s e $30^{\circ} \mathrm{W}, 80^{\circ} \mathrm{W}$ ) entre 2004 e 2011 , através da comparação com a média mensal e limiar de seis localidades. Ao comparar as duas maiores sequências de dias abaixo do limiar (05 dias em cada evento) no período de estudo para meses distintos, constatou-se decaimento da coluna total de ozônio para o mês de maio de 2010 devido à circulação Brewer-Dobson que mistura o ar pobre em ozônio da região tropical com o ar da região Antártica. $O$ mês de outubro de 2010 apresentou decaimento devido ao efeito secundário (origem Antártica). Percebeu-se que os valores apresentados durante os eventos de decaimento da coluna total de ozônio no mês de maio são menores que os decorrentes do efeito secundário em outubro.
\end{abstract}

Palavras-chave: Ozônio, América do Sul, OMI, radiação UV.

\begin{abstract}
Ozone (O3) is less than 1\% of Earth's atmospheric gases. However, it is essential for life on Earth because it absorbs ultraviolet radiation (UV-B), which is bad for the health of living beings. Since the beginning of 1980 it was reported that there was depletion in the ozone layer over Antarctica and that this could move to lower latitudes. The main objective of this work is the analysis of the main events of total ozone decay over southern South America $\left(20^{\circ} \mathrm{S}, 40^{\circ} \mathrm{S}\right.$ and $\left.30^{\circ} \mathrm{W}, 80^{\circ} \mathrm{W}\right)$ for the period between 2004 and 2011 through comparison with the monthly average of six locations. When comparing the months of May and October for the year 2010 (two major consequent days under the threshold), values of ozone total column much lower than October were found, because of the Brewer-Dobson circulation that mixes the air poor in ozone in the tropical region with the air in the Antarctic region, where the ozone hole was found during the months of winter and spring.
\end{abstract}

Keywords: Ozone, South America, OMI, UV radiation.

*laisschmalfuss@hotmail.com

Recebido: 31/01/2014 Revisado: 19/05/2014 Aceito: 15/07/2014 


\section{Introdução}

$\mathrm{O}$ O ozônio $\left(\mathrm{O}_{3}\right)$ absorve a radiação ultravioleta do tipo B (UV-B), que é prejudicial à saúde de seres vivos que habitam a superfície e podem causar uma variedade de problemas de saúde aos seres humanos e plantas (WHO, 1994). A maior concentração de $\mathrm{O}_{3}$ está centrada na estratosfera, devido à forte incidência de radiação UV que juntamente com as moléculas de oxigênio existentes nessa camada produzem seu conteúdo (SLUSSER et al., 1999). Apesar de a região tropical ser a maior produtora de ozônio estratosférico, devido à maior incidência de radiação, uma circulação meridional de ozônio estratosférico explica a maior concentração de seu conteúdo na região Antártica, pela circulação Brewer-Dobson (BREWER, 1949; DOBSON, 1968). Essa circulação consiste em uma convergência na região tropical que atinge a estratosfera, e faz o transporte horizontal de massas de ar até divergir sobre as latitudes médias e altas (SOLOMON, 1999).

Segundo Schmalfuss (2013) tanto a média mensal da coluna total de ozônio quanto seu limiar (media - 1,5 desvios padrão), mostra que quanto mais se aproximam os meses de primavera (agosto, setembro, outubro e novembro), há uma maior variabilidade da coluna total de ozônio ao longo das faixas de latitudes na região mais ao sul do continente Sul Americano. Conforme destacado por Dobson (1968), essa maior variabilidade próxima à primavera ocorre devido à forte circulação de oeste do vórtice que se forma sobre a Antártica durante o inverno e impede que ocorra transporte meridional de conteúdo de $\mathrm{O}_{3}$, assim há uma maior concentração desse componente entre as latitudes de $30^{\circ} \mathrm{S}$ e $70^{\circ} \mathrm{S}$. Os meses com menor variabilidade de coluna total de ozônio, sobre a região de estudo, são os meses mais próximos ao outono (fevereiro, março, abril e maio) (SCHMALFUSS, 2013). Isso ocorre devido à maior homogeneidade de incidência de radiação solar na estação do verão, e ao desaparecimento do vórtice na região Antártica, tendo assim um transporte meridional sem barreiras (FARMAN, 1985).

Em 1985 foi identificada uma grande diminuição no conteúdo de ozônio na atmosfera da Antártida (FARMAN, 1985), e constatou-se que essa queda ocorria durante as primaveras do hemisfério sul (HS), e que não se restringia apenas a região Antártica. Segundo KIRCHHOFF ET al. (1996), massas de ar pobre em coluna total de ozônio podem se despreender do vórtice sobre a Antártida, e migrar para latitudes mais baixas, principalmente nos meses de primavera no HS, são os chamados efeitos secundários do buraco de ozônio Antártico. Estima-se que uma redução de $1 \%$ do teor de $\mathrm{O}_{3}$ provoca um aumento de $1,2 \%$ na radiação ultravioleta incidente na superfície da Terra (KRZÝSCIN, 1996).

A região sul da América do Sul é bastante afetada por efeitos secundários do buraco de ozônio Antártico durante as primaveras austrais, ou seja, quando o vórtice que envolve o buraco de ozônio da Antártica perde suas forças devido ao fim da noite polar (LIOU, 2002), e permite que massas de ar pobres em ozônio se desprendam e migrem para latitudes menores (KIRCHHOFF ET al., 1996).

O interesse por estudar a região mais ao sul da América do Sul vem devido aos registros de casos de efeitos secundários do buraco de ozônio Antártico reportados por diversos autores como, Kirchhoff (1996), Bertagnolli (2006), Pereira (2009), Peres (2010), Hupfer (2011), os quais mostram quedas da coluna total de ozônio sobre regiões em médias latitudes. Porém estes trabalhos abrangem apenas dados pontuais, utilizando o instrumento Brewer instalado no Observatório Espacial do Sul, em São Martinho da Serra-RS, que realiza medidas indiretas da coluna total de ozônio a partir do solo. Os dados de sensores instalados em satélite como o sensor Total Ozone Mapping Spectrometer (TOMS) e Ozone Monitoring Instrument (OMI) da NASA, serviram apenas para complementar as falhas do sensor em solo, além de alguns casos com uso de ozoniossondas (KIRCHHOFF, 1996).

Com base no exposto, esse trabalho pretende realizar uma análise do comportamento da coluna total de ozônio a partir de dados do sensor OMI, para o período entre 2004 e 2011. Essa análise é realizada baseada nas climatologias e nos limiares mensais (para determinação de eventos fortes de decaimento da coluna total de $\mathrm{O}_{3}$ ), para pontos sobre seis cidades sobre a América do Sul. Pretende-se ainda, analisar a origem da massa de ar (polar ou tropical) para dois casos, os quais devem estar em meses distintos, e apresentarem maior número de dias de decaimento da coluna total em sequência.

\section{Metodologia}

A análise realizada é baseada na média mensal sobre a região sul da América do Sul (latitudes entre $20^{\circ} \mathrm{s}$ e $60^{\circ} \mathrm{s}$ e longitudes entre $30^{\circ} \mathrm{W}$ e $80^{\circ} \mathrm{W}$ ) (SCHMALFUSS, 2013). Utilizou-se o limiar de 1,5 de desvio padrão para identificação de eventos com decaimento significativo da coluna total de ozônio sobre a região de estudo (equação 1) (PINHEIRO, 2010; SCHMALFUSS, 2013). Este limiar é utilizado uma vez que, se fosse utilizado apenas 1,0 desvios padrão, as flutuações em torno da média seriam em torno de 3\% (variação esta que usualmente ocorre devido à variação do ozônio troposférico). Se utilizássemos 2,0 desvios padrões às flutuações em torno da média seriam de $7 \%$, porcentagem que provavelmente excluiria eventos de efeito secundário do buraco de ozônio Antártico (PINHEIRO, 2010; PERES, 2013).

A climatologia e o limiar foram realizados a partir dos dados do sensor OMI da NASA, com resolução temporal média diária e espacial de $1^{\circ} \times 1^{\circ}$, para o período compreendido entre outubro de 2004 e dezembro de 2011.

A seleção de seis cidades foi feita para pontos localizados abaixo da latitude de $40^{\circ} \mathrm{s}$, pois se deseja excluir as regiões onde o buraco de ozônio Antártico 
age diretamente (latitudes próximas ao polo). Assim os pontos ficaram localizados entre as latitudes de $20^{\circ}$ s e $40^{\circ} \mathrm{s}$ e entre as longitudes de $30^{\circ} \mathrm{W}$ e $80^{\circ} \mathrm{W}$, sobre a área continental (Figura 1).

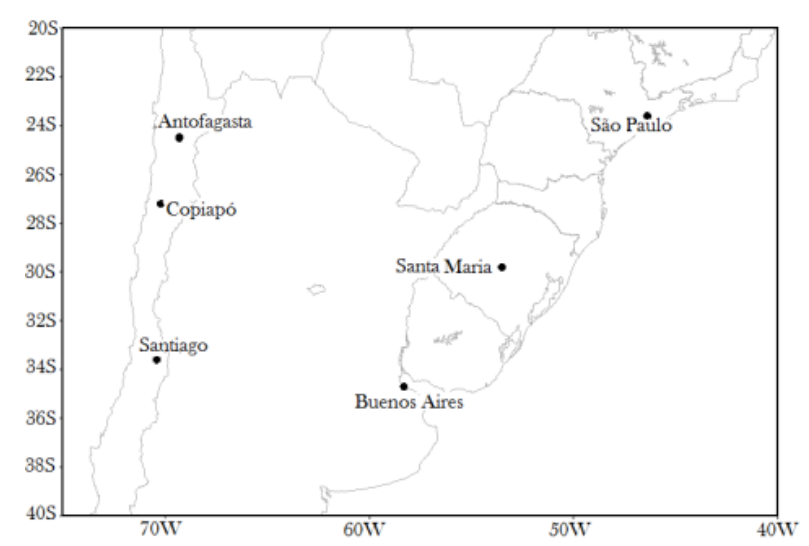

Figura 1 - Mapa das cidades selecionadas para a análise da coluna total de $\mathrm{O}_{3}$.

Para essas seis cidades e a partir de suas respectivas médias e limiares, foi contabilizado quantos dias a coluna total de ozônio esteve abaixo desse limiar estabelecido, mensalmente, para o período compreendido entre outubro de 2004 e dezembro de 2011. Identificando as datas de ocorrência foi possível verificar sequências (maior que 04 dias) de dias que apresentaram valores abaixo deste limiar. As duas maiores sequências, de meses distintos, foram selecionadas como os dois casos a serem analisados.
A análise dos dois casos selecionados foi realizada a partir do campo de coluna total de ozônio pelos dados do sensor OMI. Seguido da análise da vorticidade potencial em superfície isentrópica, para o nível de 620k para a identificação da origem da massa de ar (BENCHERIFE et al. 2003; 2011; SEMANE et al., 2006; BRACCI et al., 2012). Utilizando dados de vento e temperatura em vários níveis (1000 a 10mb), pelos dados do National Centers for Environmental Prediction/ Atmospheric Research (NCEP/ NCAR), com resolução temporal diária e de $0,5^{\circ} \times 0,5^{\circ}$ de resolução espacial.

Limiar = média mensal-1,5desvio padrão (Equação: 1)

\section{Resultados e discussões}

A partir das médias e limiares mensais obtiveram-se os dias que estiveram abaixo do limiar mensal para cada cidade, assim como suas respectivas datas. Cruzando as datas em comum de todas as cidades podem-se encontrar as duas maiores sequências de dias em meses diferentes (05 dias em maio, e 05 dias em outubro), sendo que a sequência de maio apresenta valores mais baixos que a sequência do mês de outubro (tabela 1 ).

A Fig. 2 apresenta a média de maio e outubro, para o período entre 2004 e 2011, da coluna total de ozônio para cada cidade analisada bem como a média mensal dos valores abaixo do limiar. Percebem-se os menores valores para o mês de maio, tanto da média mensal quanto da média dos valores abaixo do limiar mensal.

Importante destacar os valores apresentados da média

Tabela 1 - Sequência de dias abaixo do limiar calculado para a coluna total de O3 em cada cidade, data e valor para o mês de maio de 2010 e outubro de 2010.

\begin{tabular}{|c|c|c|c|c|c|}
\hline Cidade & Data & $\begin{array}{l}\text { Coluna } \\
\text { total de } \\
\mathrm{O}_{3}(\mathrm{UD})\end{array}$ & Cidade & Data & $\begin{array}{l}\text { Coluna } \\
\text { total de } \\
\mathrm{O}_{3}(\mathrm{UD})\end{array}$ \\
\hline Santa Maria & 02/05/2010 & 228,5 & Santa Maria & 09/10/2010 & 267,7 \\
\hline Copiapó & 03/05/2010 & 216,2 & Antofagasta & $10 / 10 / 2010$ & 254,6 \\
\hline Buenos Aires & 03/05/2010 & 237,0 & Santiago & $11 / 10 / 2010$ & 241,5 \\
\hline Santa Maria & 03/05/2010 & 227,8 & Antofagasta & $12 / 10 / 2010$ & 238,7 \\
\hline Copiapó & 04/05/2010 & 213,3 & Buenos Aires & $13 / 10 / 2010$ & 270,1 \\
\hline Buenos Aires & 04/05/2010 & 233,4 & Santiago & $13 / 10 / 2010$ & 264,6 \\
\hline Santa Maria & $04 / 05 / 2010$ & 227,8 & & & \\
\hline Copiapó & 05/05/2010 & 222,2 & & & \\
\hline Buenos Aires & 05/05/2010 & 231,8 & & & \\
\hline Santa Maria & 05/05/2010 & 237,4 & & & \\
\hline Buenos Aires & 06/05/2010 & 241,5 & & & \\
\hline
\end{tabular}




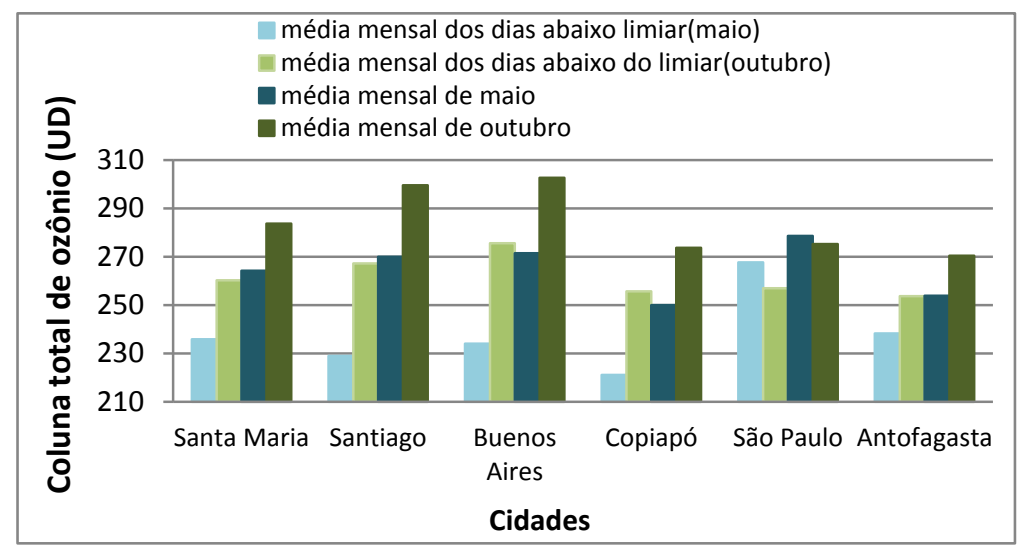

Figura 2 - Valores de coluna total de ozônio para os meses de maio (azuis) e outubro (verdes) de cada cidade. Os tons escuros representam as médias mensais, e os tons claros representam a média dos dias abaixo do limiar mensal.

mensal de maio (colunas azul escuro) ter praticamente a mesma ordem da média dos valores abaixo do limiar para o mês de outubro (colunas verde claro), para todas as cidades, exceto São Paulo que mostra uma diferença um pouco maior (aproximadamente 10UD).

O que mostra que o mês maio tem valores de coluna total de ozônio significativamente menor que o mês de outubro, indicando uma maior quantidade de incidência de radiação UV para a superfície durante todo o maio. Tabela 1 - Sequência de dias abaixo do limiar calculado para a coluna total de $\mathrm{O}_{3}$ em cada cidade, data e valor para o mês de maio de 2010 e outubro de 2010.

A Fig. 3 representa a média mensal da coluna total de ozônio de maio e outubro para o período de estudo entre 2004 e 2011, a partir dos dados do sensor OMI. A média mensal de Maio apresenta a menor variabilidade de coluna total de ozônio, sobre a América do sul (Figura 3a). Isso ocorre devido à maior homogeneidade de incidência de radiação durante o verão, e ao desaparecimento do vórtice na região Antártica, tendo assim um transporte meridional sem barreiras. Uma maior variabilidade da coluna total de $\mathrm{O}_{3}$ é observada ao longo das faixas de latitudes na região mais ao sul do continente Sul Americano na média mensal de outubro (Figura 3b). Essa maior variabilidade ocorre devido à forte circulação de oeste do vórtice que se forma durante o inverno e impede que ocorra transporte meridional de conteúdo de $\mathrm{O}_{3^{\prime}}$ assim há uma maior concentração desse componente entre as latitudes de $30^{\circ} \mathrm{S}$ e $70^{\circ} \mathrm{S}$.

Nas Figs. 4 e 5 podem ser vistos os campos de coluna total de ozônio referentes as duas sequências de dias abaixo do limiar. A Fig. 4 mostra a sequência para os dias 02 (a), 03 (b), 04 (c), 05 (d) e 06 (e) de maio de 2010, com a parte norte do continente sul Americano apresentando valores de coluna total de ozônio baixos, os quais conseguem se estender para o sul do continente alcançando a latitude de $30^{\circ} \mathrm{S}$, devido a circulação Brewer-Dobson que carrega o conteúdo de ozônio pela estratosfera em direção aos polos e latitudes médias. A Fig. 5 para os dias 09 (a), 10 (b), 11 (c), 12 (d) e 13 (e) de outubro de 2010, mostra a massa de ar de origem Antártica, trazendo ar pobre em ozônio devido ao buraco de ozônio da Antártica. Essa massa de ar pobre em ozônio começa a atingir o continente a partir do dia 11 (Figura 5.c).

Na Fig. 6, que representa o caso de maio de 2010 é possível identificar a intrusão de uma massa de ar de
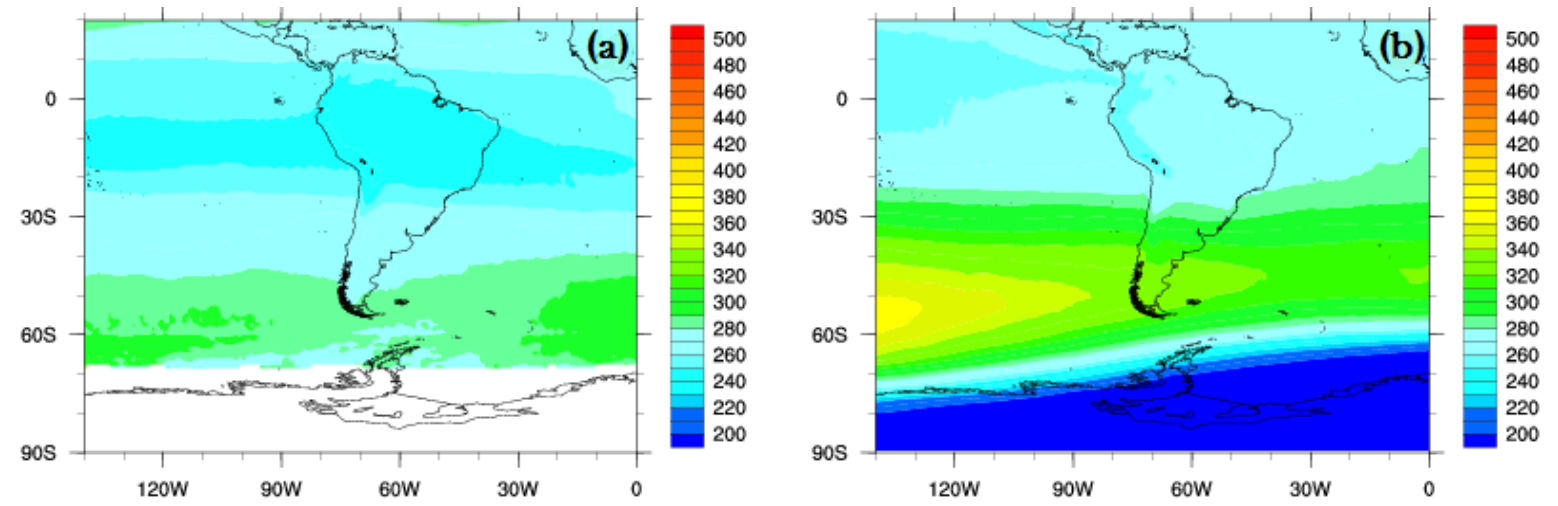

Figura 3 - Média mensal da coluna total de ozônio sobre a América do Sul para os meses de (a) maio e (b) outubro. 


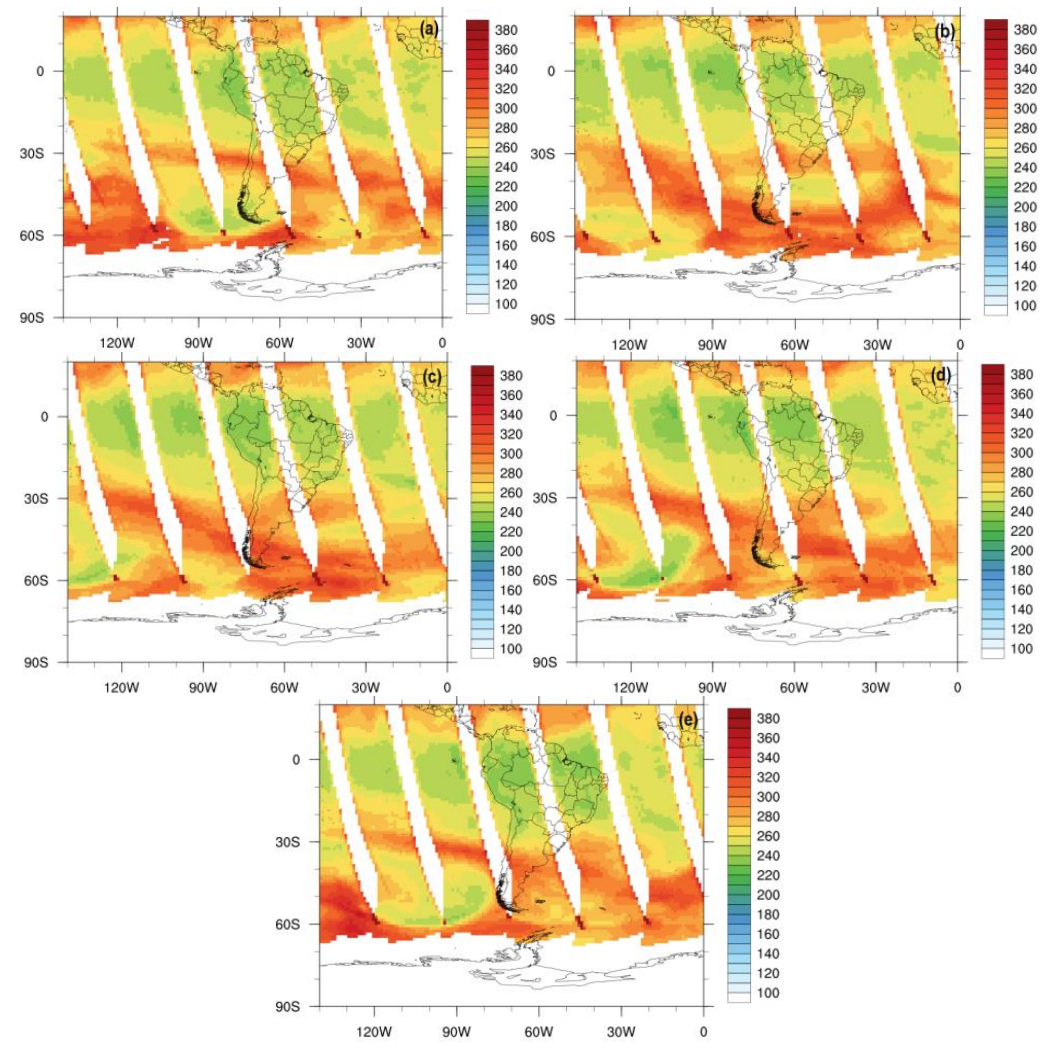

Figura 4 - Coluna total de ozônio (UD) para o caso referente ao mês de maio de 2010. (a) dia 02, (b) dia 03, (c) dia 04, (d) dia 05 e (d) dia 06.

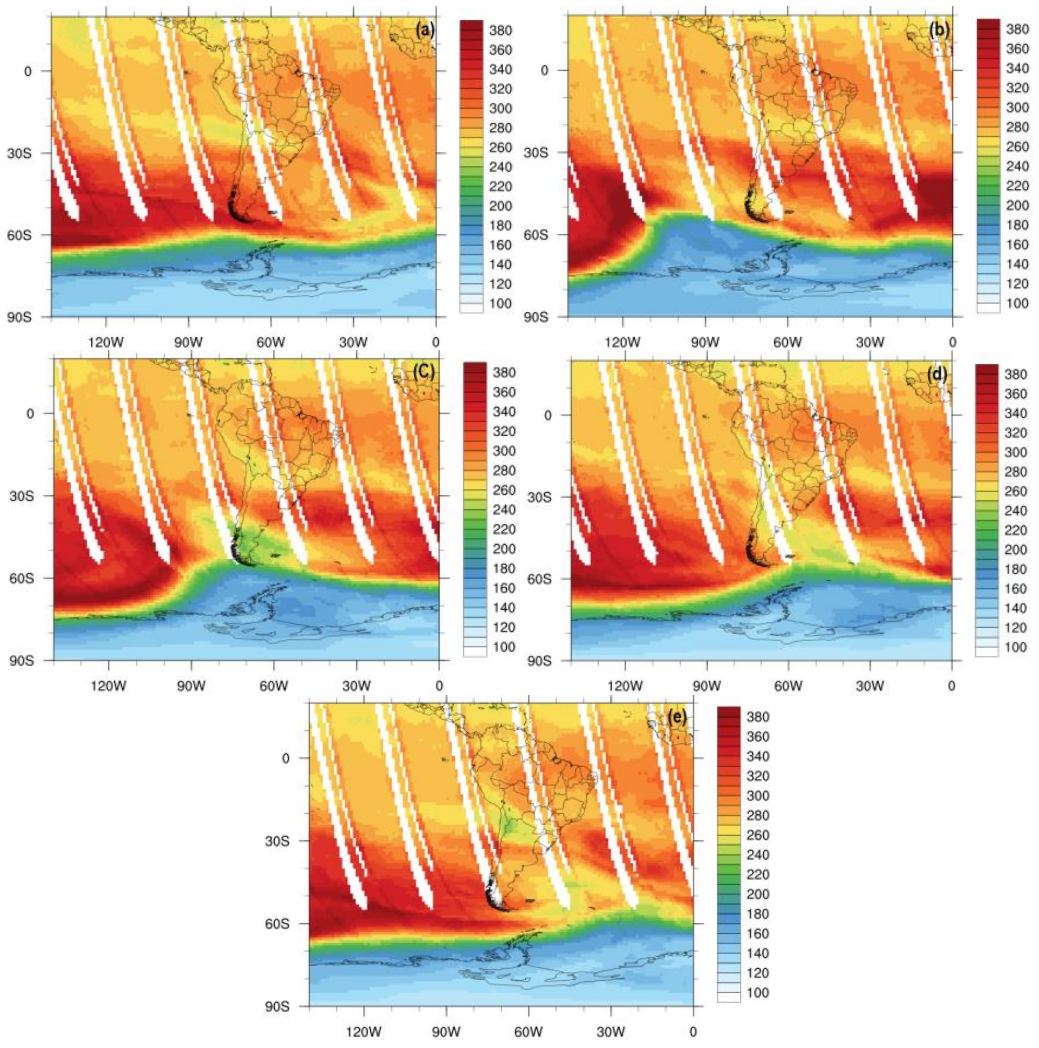

Figura 5 - Coluna total de ozônio para o mês de outubro de 2010. (a) dia 09, (b) dia 10, (c) dia 11, (d) dia 12 e (e) dia 13. 


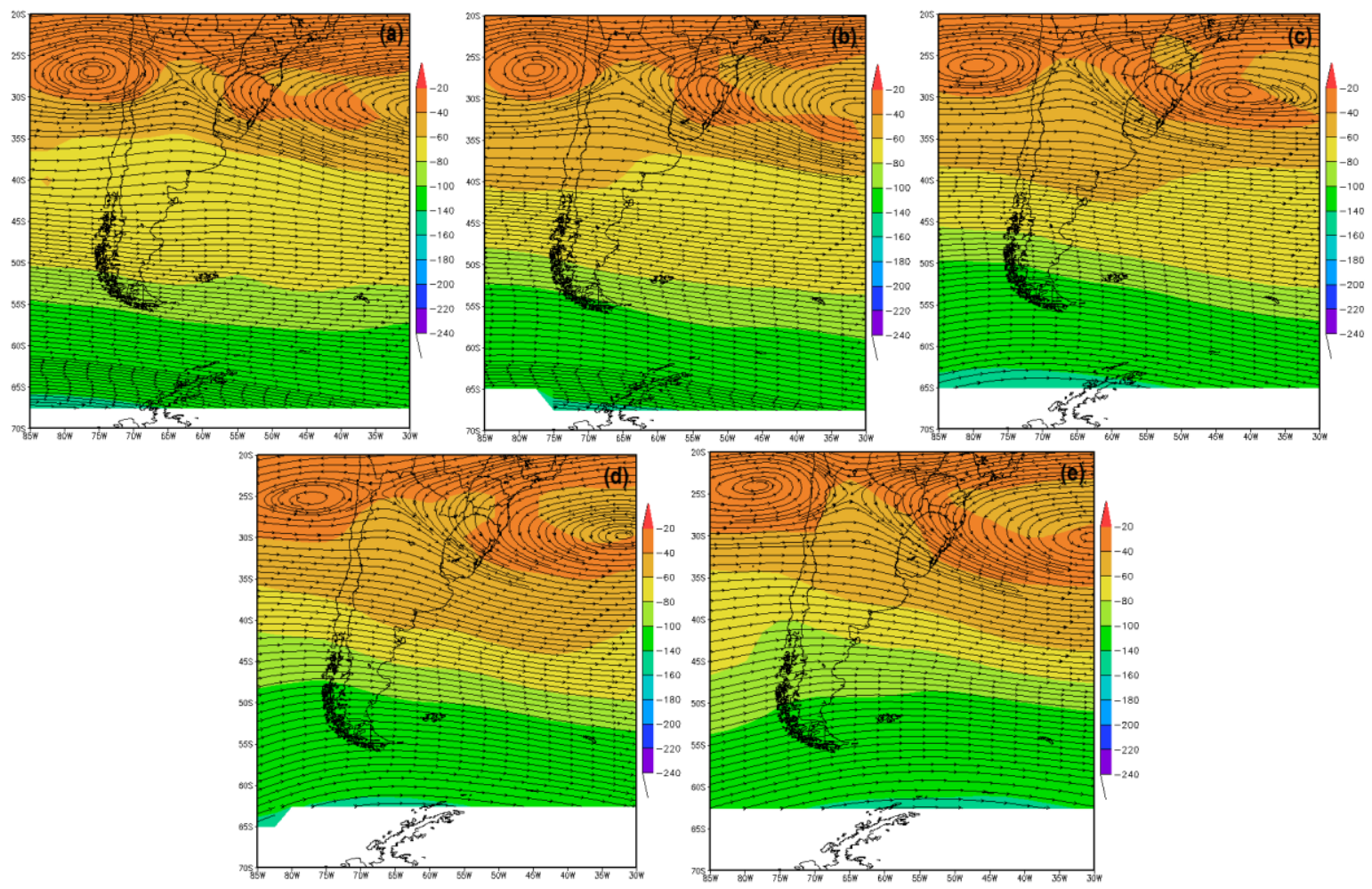

Figura 6 - Vorticidade potencial em superfície isentrópica de 620K para o caso do mês de maio de 2010, para os dias 02 (a), 03 (b), 04 (c), 05 (d) e 06 (e).
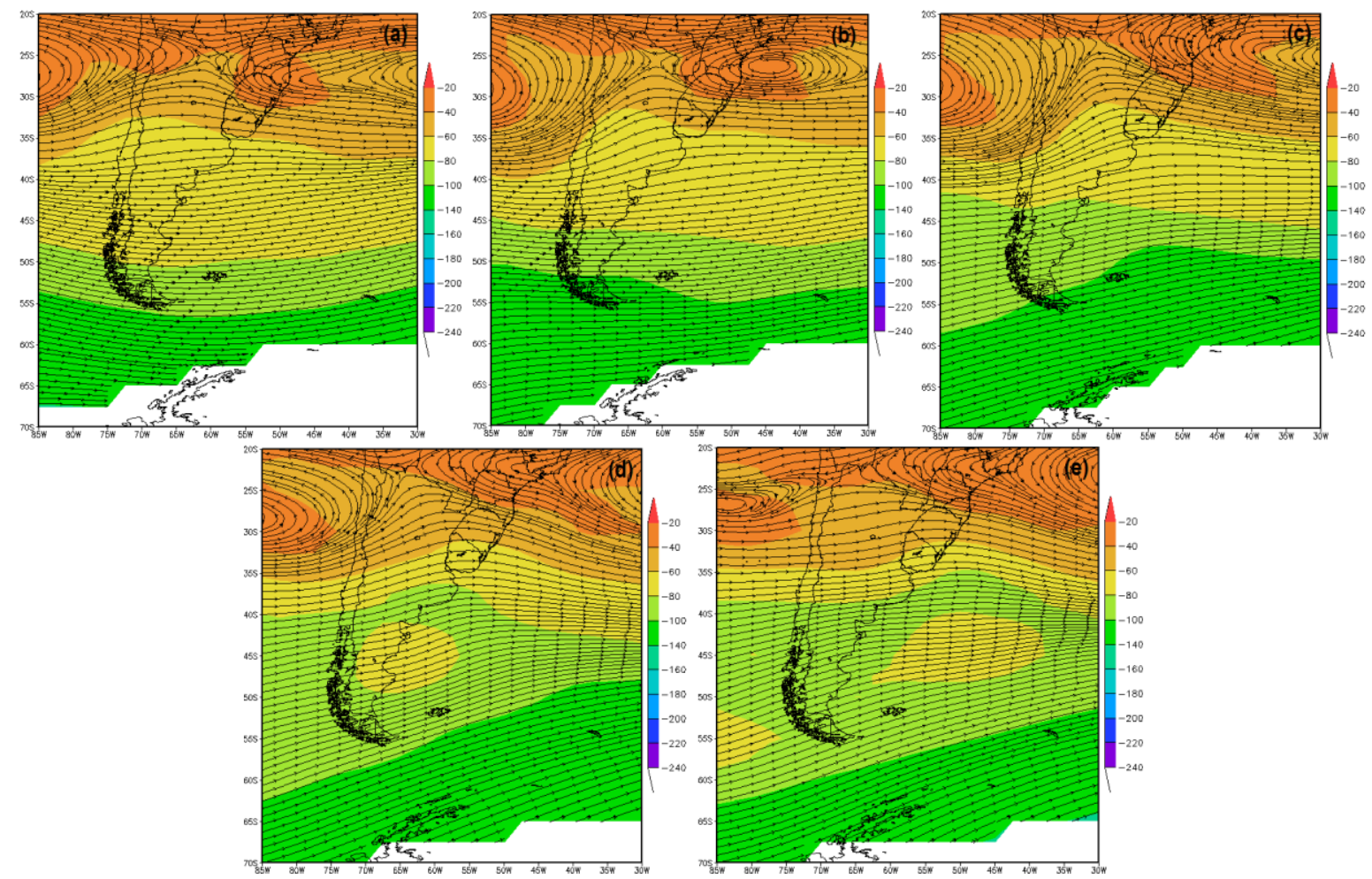

Figura 7 - Vorticidade potencial em superfície isentrópica de 620K para o caso do mês de outubro de 2010, para os dias 09 (a), 10 (b), 11 (c), 12 (d) e 13 (e). 
origem equatorial, devido à diminuição dos valores de vorticidade potencial. A Fig. 7, para o caso de outubro de 2010 confirma os baixos valores encontrados sobre as cidades Santa Maria, Antofagasta, Santiago e Buenos Aires como efeito secundário do buraco de ozônio Antártico, pois há um aumento nos valores de vorticidade potencial, decorrente da origem da massa de ar ser polar.

\section{Conclusões}

Com base na análise da coluna total de ozônio, pode-se constatar que os meses de maio e outubro apresentaram as maiores sequências de dias com valores de coluna total de ozônio abaixo do limiar estabelecido (05 dias em cada evento) sobre as cidades selecionadas.

Percebeu-se que no mês de maio há uma diminuição da coluna total de $\mathrm{O}_{3}$ bem mais significativa do que em outubro. O mês de maio apresenta baixos valores médios de coluna total de ozônio como consequência da extensão de massas de ar tropicais, portanto com a ocorrência de eventos de decaimento constatam-se episódios com valores mínimos. $\mathrm{O}$ mês de outubro apresenta valores baixos de coluna total de ozônio semelhante à média do mês de maio somente durante a presença de eventos de efeito secundário.

Dessa maneira, percebe-se a importância dos eventos de decaimento da coluna total de ozônio e sua relação com massas de ar tropicais no mês de maio para o Sul da América do Sul.

\section{Agradecimentos}

A primeira autora agradece:

Ao Programa de Pós-Graduação em Meteorologia da Universidade Federal de Pelotas (Ppgmet).

Ao Conselho Nacional de Desenvolvimento Científico e Tecnológico (CNPq).

À National Aeronautics and Space Administration (NASA) pela disponibilidade gratuita dos dados do Ozone Monitoring Instrument (OMI).

\section{Referências}

BENCHERIF, H.; PORTAFAIX, T.; BARAY, J. L.; MOREL B.; BALDY S.; LEVEAU, J.; HAUCHECORNE, A.; KECKHUT, P.; MOORGAWA A.; MICHAELIS, M. M.; DIAB, R. LIDAR observations of lower stratospheric aerosols over South Africa linked to large scale transport across the southern subtropical barrier. Journal Atmospheric and Solar-Terrestrial Physics, v.65, p.707-715, 2003.
BERTAGNOLLI, C.; POSSANI, G.; PINHEIRO, D. K.; FERREIRA, N. J.; SCHUCH, N. J. “Observação de Perturbações do Buraco de Ozônio Antártico na Região Central do Rio Grande do Sul no Ano de 2000 através de Ondeletas". CONGRESSO DE INICIAÇÃO CIENTÍFICA E TECNOLOGIA EM ENGENHARIA, 21. 2006. Ijuí-RS. Anais... Ijuí-RS, 2006.

BRACCI, A.; CRISTOFANELLI, P.; SPRENGER, M.; BONAFE, U.; CALZOLARI, F.; DUCHI, R.; LAJ, P.; MARINONI, A.; ROCCATO, F.; VUILLERMOZ, E.; BONASONI, P. Transport of Stratospheric Air Masses to the Nepal Climate ObservatoryPyramid (Himalaya; 5079 m MSL): A Synoptic-Scale Investigation. Journal of Applied Meteorology and Climatology, v.51, n.8 , p.1489-1507, 2012.

BREWER, A. W. Evidence for a world circulation provided by the measurements of helium and water vapour distribution in the stratosphere, Quarterly Jounal of the Royal Meteorological Society, v.75, p.351-363, 1949.

DOBSON, G.M.B. Ozone in the Atmosphere. Exploring the Atmosphere. 2ed. Oxford: University Press, 1968.

FARMAN, J. C.; GARDINER, B. G.; SHANKLIN, J., D. Large losses of total ozone in Antarctica reveal seasonal $\mathrm{ClOx} / \mathrm{NOx}$ interaction. Revista Nature, v. 315, p. 207-210, mai. 1985.

\section{HUPFER N.T.; KALL E.; PERES L.V.; PINHEIRO} D.K.; SCHUCH N.J.; LEMES N.M.P. Comparação da radiação ultravioleta quando da ocorrência dos eventos de efeitos secundários do buraco de ozônio Antártico sobre o sul do Brasil dos dias 16/10/2003 e 28/09/2008. CONGRESSO INTERNACIONAL DA SOCIEDADE BRASILEIRA DE GEOFÍSICA, 12. 2011 Rios de Janeiro-RJ. Anais... Rio de Janeiro-RJ, 2011.

KIRCHHOFF, V. W. J. H.; SCHUCH, N.J.; PINHEIRO, D. K.; HARRIS, J.M. Evidence for an Ozone Hole Perturbation at 30o South. Atmospheric Environment, v.30, n.9, p.1481-1488, 1996.

KZRÝSCIN, J.W. UV controlling factors and trends derived from the ground-based measurements taken at Balsk, Poland, 1976-1994. Journal of Geophysical Research. v.101, n.11, p.16797-16804. 1996.

LIOU K.N. An Introduction to Atmospheric Radiation. 2ed. International Geophysics Series. v.84. Academic Press. 2002. 
PEREIRA, N. Análise da ocorrência de eventos de efeitos secundários do buraco de ozônio Antártico sobre o sul do Brasil. 2009. 52f. Relatório final de projeto de iniciação científica PIBIT/INPE-CNPq/ MCT. Curso de Meteorologia. Universidade Federal de Santa Maria. Santa Maria.

PERES, L.V. Análise da ocorrência dos eventos de efeitos secundários do buraco de ozônio antártico sobre o sul do Brasil. 2010. 56f. Relatório final de projeto de iniciação científica PIBIT/INPE-CNPq/ MCT. Universidade Federal de Santa Maria. Santa Maria.

PERES, L. V. Efeito secundário do buraco de ozônio Antártico sobre o Sul do Brasil. 2013. 178f. Dissertação (Mestrado em Meteorologia)Faculdade de Meteorologia, Universidade Federal de Santa Maria, Santa Maria.

PINHEIRO, D.K; LEME, N.P.; PERES, L.V.; KALL, E. Influence of the Antartic ozone hole over the south of Brazil in 2008 and 2009. Annual Activity Report 2010. National Institute of Science and Tachnology Antarctic Environmental Research. p.33-37. 2010.

SCHMALFUSS, L. SM. Médias e limiares mensais da coluna total de ozônio sobre o sul da América do Sul. WORKSHOP BRASILEIRO DE MICROMETEOROLOGIA, oito. 2013. Santa Maria - RS. Anais... Santa Maria - RS, 2013.

SEMANE, N.; BENCHERIF, H.; MOREL, B.; HAUCHECORNE, A.; DIAB, R. D. An unusual stratospheric ozone decrease in Southern Hemisphere subtropics linked to isentropicair-mass transport as observed over Irene (25.5 $\left.\mathrm{S}, 28.1^{\circ} \mathrm{E}\right)$ in mid-May 2002. Atmospheric Chemistry and Physics, v.6, p.1927-1936, 2006.

SLUSSER, J.; GIBSON, J.; BIGELOW, D.; KOLINSKI, D.; MOU, W.; KOENIG, G. \& BEAUBIEN, A. Comparison of column ozone retrievals by use of an UV multifilter rotating shadow-band radiometer with those from Brewer and Dobson spectrophotometers. Applied Optics, v.38, n.9, p.1543-1551, 1999.

SOLOMON, S. Stratospheric ozone depletion: a review of concepts and history. Reviews of Geophysics, v.37, n.3, p.275-316, 1999.

WHO - World Health Organization. Ultraviolet radiation. Environmental Health Criteria 160, Geneva, 1994. 